\title{
Photo-Induced DNA-Dependent Conformational Changes in Silver Nanoparticles
}

\author{
Vasil G. Bregadze ${ }^{1}$, Zaza G. Melikishvili ${ }^{2}$, Tamar G. Giorgadze ${ }^{1}$ \\ ${ }^{1}$ Department of Biological System Physics, Ivane Javakhishvili Tbilisi State University, \\ Elevter Andronikashvili Institute of Physics, Tbilisi, Georgia \\ ${ }^{2}$ Department of Coherent Optics and Electronics, Georgian Technical University, \\ Vladimir Chavchanidze Institute of Cybernetics, Tbilisi, Georgia \\ Email: v.bregadze@aiphysics.ge,vbregadze@gmail.com
}

Received December 27, 2012; revised January 29, 2013; accepted February 5, 2013

Copyright (C) 2013 Vasil G. Bregadze et al. This is an open access article distributed under the Creative Commons Attribution License, which permits unrestricted use, distribution, and reproduction in any medium, provided the original work is properly cited.

\begin{abstract}
The goal of the present investigation is to study the interaction of AgNPs with thymus DNA by traditional and original spectra-photometric and thermo-dynamic methods and approaches in darkness and under photo-irradiation. 1) At the interaction of DNA with nano-particles hypsochromic shift of $6 \mathrm{~nm}$ and hypochromic effect of $20 \%$ of AgNPs absorption band are observed. 2) At photo-irradiation ( $\lambda=436 \mathrm{~nm}$ or full spectrum of visible band) of AgNPs-DNA complexes absorption spectra band width is changed from $140 \mathrm{~nm}$ to $360 \mathrm{~nm}$ at half-height. Besides, isosbestic point is observed. 3) Kinetic study of photo-diffusion has made it possible to determine desorption rate constant and desorption reaction activation energy that are equal respectively to $k_{d} \cong 9 \times 10^{-5} \mathrm{~s}^{-1}, E_{d} \cong 80 \mathrm{~kJ} / \mathrm{M} \mathrm{Ag}^{0}$ for AgNPs bound with DNA. It is shown that AgNPs represent liquid drops which moisture the DNA surface at interaction. At photo-irradiation of AgNPs-DNA complex DNA dependant conformational transition takes place due to fast and intensive heating.
\end{abstract}

Keywords: Component; DNA-Silver Nanoparticle Complexes; Optical Spectroscopy of Intermolecular Interactions; Photo-Dynamic Effect; Silver Nanoparticles; Silver Ions

\section{Introduction}

One of interesting tendencies in nano-technology is the application of metal nanoparticles in cancer photo-chemo and photo-thermotherapy. For the purpose it is important to choose materials and sizes of nanoparticles that are capable for: 1) conformational changes; 2) diffusion and 3) chemical transformations in the presence of DNA, light, temperature, ionic strength, redox agents and agents changing environment polarity. Silver nanoparticles (AgNPs) having the size not more than $10 \mathrm{~nm}$ can serve as a fine example of such material [1].

It is hard to overstate the role of metal ions, especially transition ones, in vital activity of organisms. Particular interest causes the interaction of metal ions such as $\mathrm{Pt}(\mathrm{II}), \operatorname{Ag}(\mathrm{I}), \mathrm{Cu}(\mathrm{I})$ with DNA because metal induced point defects in DNA [2-4] can lead to point mutations and can participate in formation of crosslinks between the chains of DNA. One of the interesting examples is the application of cis-diamine-dichlorine-platinium and so-called photo-cis-platinium for tumor treating. More and more articles have been published lately where the usage of metal nanoparticles, particularly gold [5-9] and carbon [10,11] ones, for tumor photo-thermo-therapy is discussed.

Silver nano-particles for our investigation were chosen for the following reason. Having the size $1-2 \mathrm{~nm}$ they easily pass the cell membrane and penetrate into the nuclei, the pores of which do not exceed $8-9 \mathrm{~nm}$, and can interact with DNA. AgNPs of this kind can be strongly heated and thus, more successfully used in photo-thermotherapy.

The goal of the present investigation is to study the interaction of AgNPs $(1-2 \mathrm{~nm})$ with thymus DNA by spectroscopic and thermodynamic methods in darkness and under photo-irradiation.

\section{Materials and Method}

Colloidal silver suspension with particle sizes of $1-2 \mathrm{~nm}$ in distilled water $(200 \mu \mathrm{g} / \mathrm{ml})$ was purchased from DDS Inc., D/B/A/, Amino Acid \& Botanical Supply P.O. Box 
356, Cedar Knolls, NJ 07927.

Calf thymus DNA produced by Sigma was dissolved in $0.01 \mathrm{M} \mathrm{NaNO}_{3}$ solution-background electrolyte, $\mathrm{pH}$ $\cong 6$. DNA concentration was evaluated by UV absorption spectrophotometer. Molecular extinction factor was $\varepsilon^{\prime}$ $=6600 \mathrm{~cm}^{-1} \mathrm{M}^{-1}(\mathrm{P}), \lambda=260 \mathrm{~nm}$.

Registration of absorption spectra of AgNPs was carried out by optical fiber spectrometer AvaSpec ULS 2048-USB 2.

Photoirradiation was carried out in reactor with the fixed light beam in $1 \mathrm{~cm}$ rectangular fluorescent quartz cell. In the same cell with the interval of 5 min absorption spectra of irradiated solutions were registered by AvaSpec spectrometer. Before each absorption Registration the cell was shut to protect the solution from photo irradiation. Registration time was $8 \mathrm{msec}$. As a source of radiation xenon arch discharge lamp with rating of $35 \mathrm{~W}$ in glass balloon was used. To irradiate the solution water filter and light filter with light wave transmission $\lambda=436 \mathrm{~nm}$ were used. Radiation power in the cell was $300 \mathrm{~mW}$ for thermal water filter and 15 $\mathrm{mW}$ for water filter matched with light filter $(\lambda=436$ $\mathrm{nm})$.

\section{Results and Discussions}

Figure 1(a) shows the absorption spectra of AgNPs and AgNPs-DNA complexes. Figure 1(b) presents first derivatives of absorption spectra of AgNPs and AgNPs in the complex with the DNA.

The analysis of Figures 1(a) and (b) shows that at DNA interaction with AgNPs a short-wave shift of AgNPs absorption band $(6 \mathrm{~nm})$ takes place. Besides, there can be observed a $20 \%$ hypochromic effect.

Figure 2 shows AgNPs absorption spectra before and after their heating followed by their cooling. Colloidal silver suspension was placed in hermetic test-tube and it was being incubated in a vessel with boiling water for 15 $\min$. Then the test-tube with the sample was cooled in ice-bath to room temperature. It can be seen from Figure 2 that nanoparticles exposed to heating demonstrate noticeable weakening of absorption intensity, and what is very important, widening of absorption spectra from 140 $\mathrm{nm}$ to $215 \mathrm{~nm}$.

Hypsochromic shift and widening of AgNPs absorption spectra caused by their interaction with DNA and heating demonstrates, on the one hand, loosening of AgNPs, i.e., penetration of solvent (water), the molecules of which show weaker polarizability $[12,13]$, inside nanoparticles (Figures 1(a) and (b)), and on the other hand, change of nanoparticle size and form (Figure 2). De crease of intensity is due to partial corrosion of AgNPs in the presence of DNA [1].

The company nanoComposix $[14,15]$ gives sample

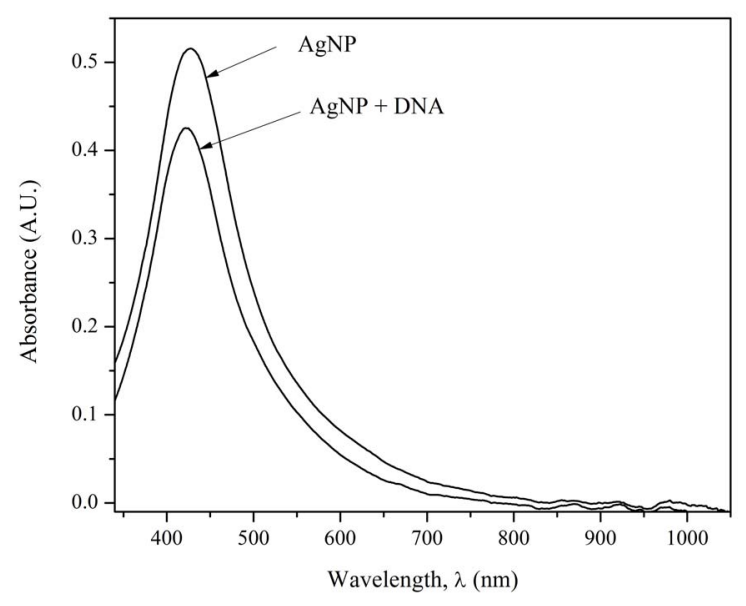

(a)

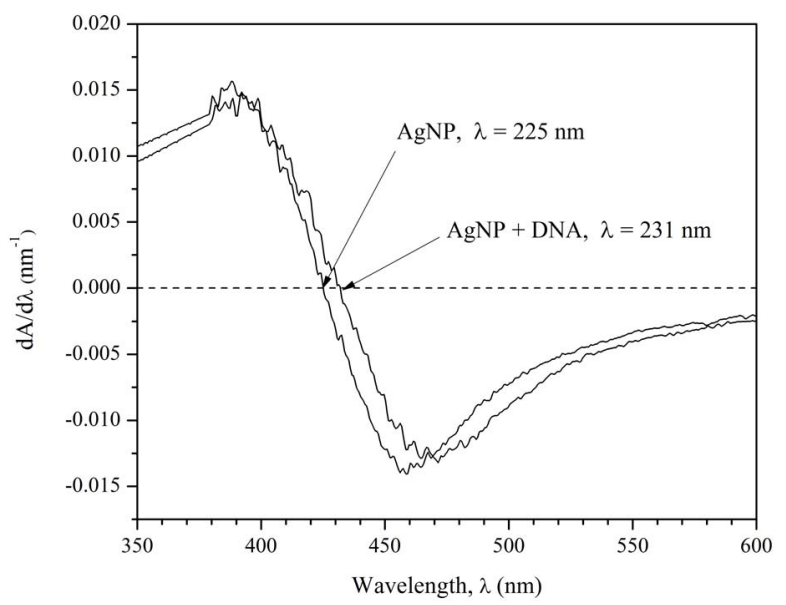

(b)

Figure 1. (a) Absorption spectra of AgNPs and AgNPs-DNA complexes. [AgNPs]-0.72 $\times \mathbf{1 0}^{-4} \mathrm{M}\left(\mathrm{Ag}^{0}\right),[\mathrm{DNA}]-1.6 \times$ $10^{-4} \mathrm{M}(\mathrm{P})$, [NaNO3] $-10^{-2} \mathrm{M}$; (b) Fist derivative spectra of AgNPs and AgNPs-DNA. The blue shift is evident.

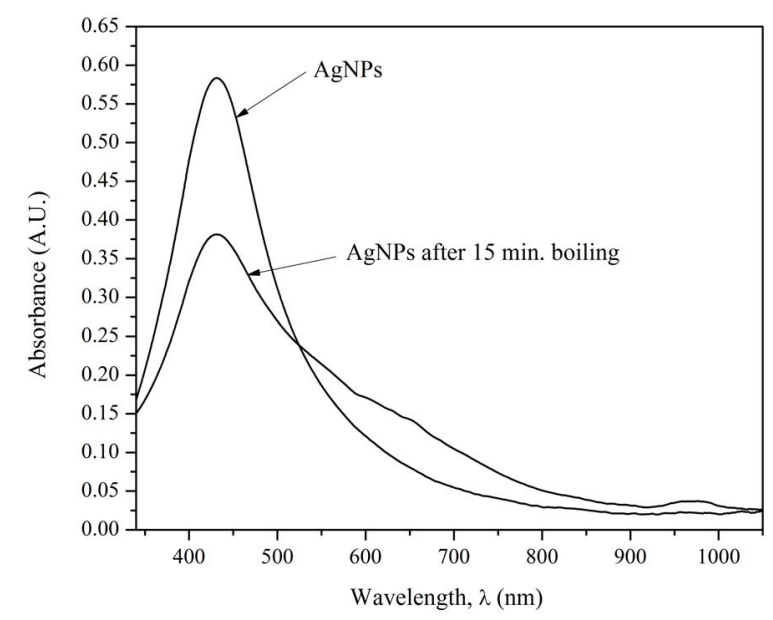

Figure 2. Absorption spectra of AgNPs before (1) and after (2) heating processing (15 min incubation at $\mathrm{T}=373 \mathrm{~K}$ ) $[\mathrm{AgNPs}]-0.72 \times \mathbf{1 0}^{-4} \mathrm{M}\left(\mathrm{Ag}^{0}\right),\left[\mathrm{NaNO}_{3}\right]-10^{-2} \mathrm{M}$. 
absorption spectra for spherical AgNPs with particle sizes of 10, 20, 30, 40, 50, 60, 70, 80, 90 and $100 \mathrm{~nm}$ at the same mass concentration $0.02 \mathrm{mg} / \mathrm{ml}$. The given data show that with the increase of the size of the particles widening of the red shift of absorption band can be observed. It is notable that despite the growth of the particle size, i.e., decrease of their total number in the solution, the intensity of absorption bands for nanoparticles with the sizes from 10 to $40 \mathrm{~nm}$ is not practically changed, only a small shift of absorption band maximums can be observed. The above explicitly points out that chromophore units are silver atoms and not nanoparticles. Thus, we can draw a conclusion that silver atoms in AgNPs are sufficiently isolated and bound together by dispersion interaction (induced dipole-induced dipole). As these interactions are performed in water surrounding they should be considerably amplified at the expense of so called hydrophobic effect [16], that means compaction and then minimization of the surface (decrease of the system entropy).

We should especially point out that in nanoparticle, which consists of one kind of atoms, along with the mentioned dispersal interaction, the so-called resonance interaction should take place [17]. Such types of interactions are typical for molecular crystals and they usually lead to exiton splitting of the principal absorption band. Inevitable condition for exiton splitting is the presence of a system consisting of identical groups and having hard structure [18]. The absence of splitting can mean that AgNPs under investigation (Figure 1) have liquid structure resembling a drop which under definite conditions (such as temperature, photo-irradiation, variations in dielectric constant of the environment) should be characterized by conformational transitions. So, once again analyzing absorption spectra presented in Figure 1 we can make the conclusion that hypsochromic shift shows not only loosening of AgNPs but moreover demonstrates the transfer of the drop into a spherical segment (wetting angle $\theta<\pi / 2$ ). It means that DNA surface is moistened by silver nano-particles. First of all it is connected with great affinity of soft ions $\left(\mathrm{Cu}^{+}, \mathrm{Ag}^{+}, \mathrm{Hg}^{++}\right.$etc. $)$and metal ions $\mathrm{M}^{0}$ with DNA double helix [4]. Photo-diffusion of AgNPs (see Figure 4) on DNA double helix resembles flesh-desorption phenomena, i.e., fast heating of AgNPs by photons, then desorption of silver ions with their following adsorption by DNA double helix, including creation of cross-links between silver atoms and DNA chains.

Kinetics of AgNPs photoirradiation has also been studied. Figures 3 and $\mathbf{4}$ show superposed absorption spectra of free AgNPs and AgNPs in complex with DNA before and after irradiation using water filter.

The analysis of the spectra on Figures $\mathbf{3}$ and $\mathbf{4}$ demonstrates that only the irradiated complexes AgNPs-DNA have distinctly expressed isosbestic point. The test with

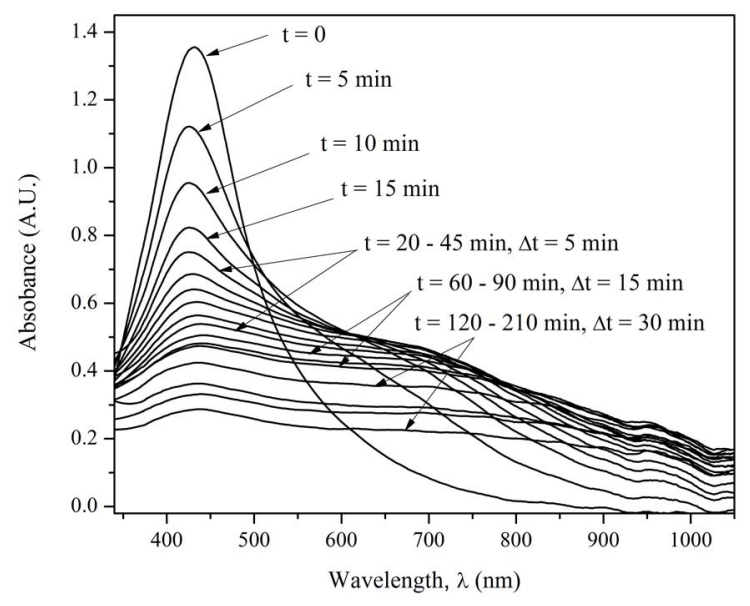

Figure 3. Absorption spectra of AgNPs before and after irradiation (5 min interval). [AgNPs]-1.94 $\times \mathbf{1 0}^{-4} \mathrm{M}\left(\mathrm{Ag}^{0}\right)$, $\left[\mathrm{NaNO}_{3}\right]-10^{-2} \mathrm{M}$.

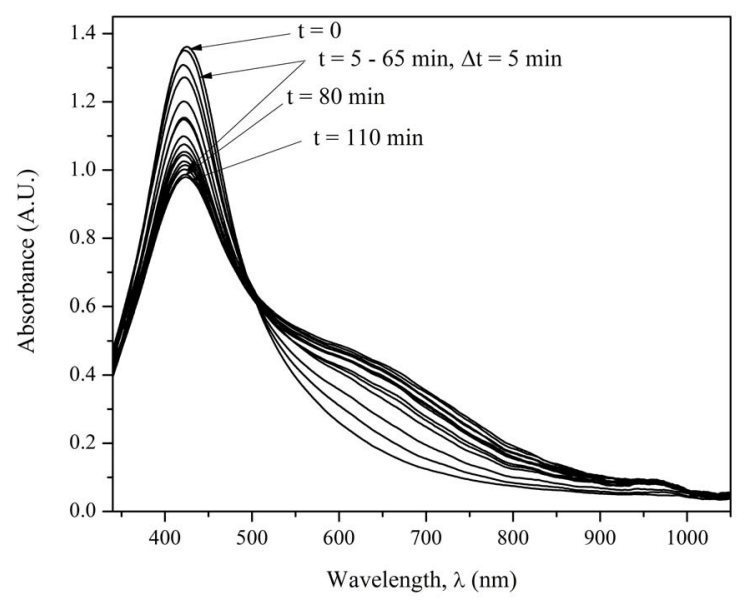

Figure 4. Absorption spectra of AgNPs-DNA before and after irradiation (5 min interval). [AgNPs] $-1.94 \times 10^{-4} \mathrm{M}$ $\left(\mathrm{Ag}^{0}\right),[\mathrm{DNA}]-1.6 \times 10^{-4} \mathrm{M}(\mathrm{P}),\left[\mathrm{NaNO}_{3}\right]-\mathbf{1 0}^{-2} \mathrm{M}$.

the free AgNPs shows that as a result of photoirradiation desorption of silver atoms and their oxidation to $\mathrm{Ag}^{+}$ions take place. The presence of isosbestic points in the absorption spectra of irradiated AgNPs-DNA complexes proves that the system has not less than two states, i.e. AgNPs-DNA complexes have several forms of existence joint by structural photo diffusive transition from one form, e.g. spherical one, to extended long and probably one-dimensional form along DNA double helix. The analysis of the spectra really shows with good correlation $(\leq 5 \%)$ that the space under the spectra is preserved which means that there are no changes in chromophore electron structure. Besides, half width of absorption spectra $\Delta \lambda_{1 / 2}$ is changed from $140 \mathrm{~nm}$ to $360 \mathrm{mn}$. Red shift and widening of AgNPs absorption band points out to increase of electron conjugation (linear and cyclic conjugated systems) typical for molecular systems [19]. 
We have also carried out evaluation of energy needed for heating of AgNPs (1 - $2 \mathrm{~nm})$. Under the condition when atomic (specific) heat capacity of liquid silver is equal to $30.5 \mathrm{~J} /(\mathrm{g}$-atom $\times$ grad $)$; single photon energy $(\lambda$ $=430 \mathrm{~nm}$ ) is $46.2 \times 10^{20} \mathrm{~J}$ it is possible to heat a single silver nano-particle (size $1 \mathrm{~nm}$ ) consisting of 30 silver atoms up to $610 \mathrm{~K}$; in case when a silver nanoparticle has a size of $2 \mathrm{~nm}$, i.e., consists of 240 atoms, it can be heated up to $340 \mathrm{~K}$. It means that photo-irradiation $(\lambda=$ $430 \mathrm{~nm}$ ) has absolute ability to cause the photo-diffusion of AgNPs, especially of those whose size is about $1 \mathrm{~nm}$.

To check the concept we have carried out thermodynamic kinetic analysis of absorption spectra of AgNPsDNA complexes (see Figure 4).

Let's consider the changes in absorption spectra for photo-irradiated AgNPs-DNA complexes given in Figure 4 versus the duration of irradiation in $M_{t} / M_{e}$ and $t^{1 / 2}$ (see Figure 5). $M_{e} \equiv A_{t=0}-A_{t=6600}$ is the number of silver atoms in nanoparticles at the beginning (absorption $A_{t}$ when $\lambda=430 \mathrm{~nm}$ at $t=0), M_{t} \equiv A_{t=0}-A_{t}$ is molar quantity of silver atoms desorbed by the time moment $t$ (difference between absorption $A_{t=0}-A_{t}$ at $\lambda=430 \mathrm{~nm}$ ). As it can be seen the curves in Figure 5 have S-shape for photo desorption kinetics of silver atoms both from the surface of free AgNPs and AgNPs-DNA complexes. Sshape curves denotes that photo-induced desorption of atoms is a complex and multiphase process [20]; it means diffusion of silver atoms from the inner part of a nanoparticle to its surface, conformational changes in the particles especially in those ones that are adsorbed on DNA surface. Next we are going to consider the results given in Figures 3 and 4 in $\ln \left[M_{e} /\left(M_{e}-M_{t}\right)\right]$ and $t$ coordinates, which are given in Figure 6.

The analysis of the curve shows that only initial stage of the given curves of desorption kinetics obey linear law of Langmuir first-order equation

$$
\ln \left[M_{e} /\left(M_{e}-M_{t}\right)\right]=k t \text {. }
$$

The constant of desorption rate of silver atoms from the surface of AgNPs has been evaluated from the slopes of the curves and the data is: for AgNPs bound with DNA $k_{d} \cong 9 \times$ $10^{-5} \mathrm{~s}^{-1}$. The values allow us to estimate activation energy $E_{d}$ for desorption reaction using the equation

$$
k_{d}=v_{0} \exp \left(-E_{d} / R T\right),
$$

where $v_{0}$ is pre-exponential factor assumed as $v_{0} \approx 10^{10}$ $\mathrm{s}^{-1}$ (reciprocal quantity to silver atom oscillation time in nanoparticles). In this case, we have acquired the value for $E_{d} \cong 80 \mathrm{~kJ} / \mathrm{M} \mathrm{Ag}^{0}$ for AgNPs bound with DNA at $T=$ $300 \mathrm{~K}$. As $E_{d}=E_{a}+Q_{a}$, where $\mathrm{E}_{\mathrm{a}}$ is adsorption activation energy and $\mathrm{Q}_{\mathrm{a}}$ is adsorption heat of nanoparticles, so $Q_{a} \cong$ $80 \mathrm{~kJ} / \mathrm{M} \mathrm{Ag}^{0}$ under the condition that formation of nanoparticles is not an activated process. The value of heat is specific for cluster nanostructures [21].

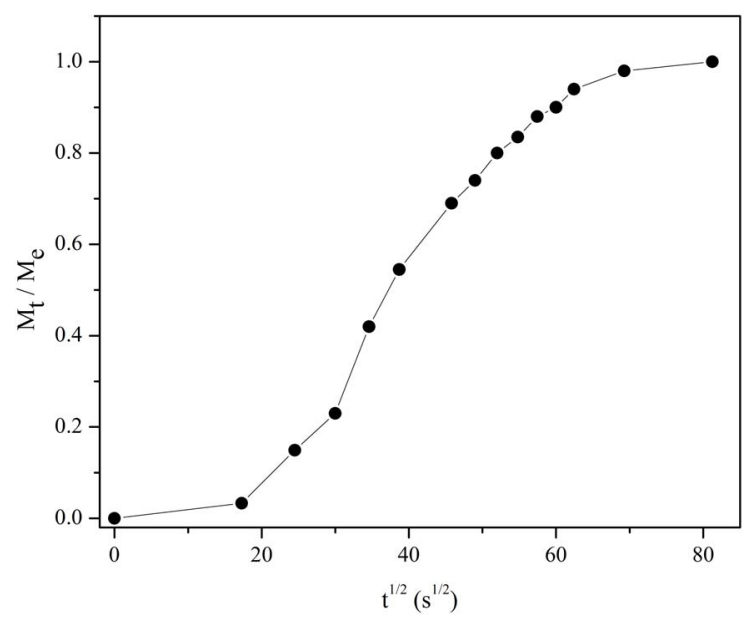

Figure 5. Kinetic curve of photo-desorption in $M_{t} / M_{e}$ and $t$ 1/2 coordinates for AgNPs bound with DNA.

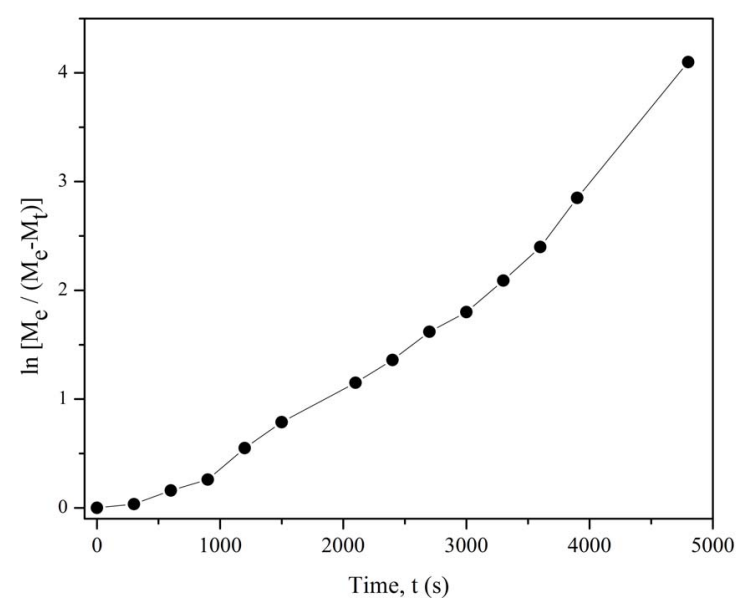

Figure 6. Kinetic curve of photo-desorption in $\ln \left[M_{e} /\left(M_{e}-\right.\right.$ $\left.\left.M_{t}\right)\right]$ and $t$ coordinates for AgNPs bound with DNA.

Next we give evaluation of life time for $\mathrm{Ag}^{0}$ complex with DNA. As far as in 1996 one of the authors [22] proposed a thermodynamic model of interaction between small ligands and DNA. Based on the example of interaction between the ions of transition metals and DNA it was shown that the life time of the complexes $\tau$ is connected to equilibrium characteristic by stability constant $K$ and equation

$$
\tau=\tau_{0} \times K
$$

where $\tau_{0}$ is the duration of the fluctuation excitation of the adsorbing ligands or molecules interacting with a solid surface and it lies between $10^{-11}$ and $10^{-10} \mathrm{~s}$. Silver atom photo-desorption from the surface of nanoparticles, included in DNA complex, has desorption activation energy of $80 \mathrm{~kJ} / \mathrm{M} \mathrm{Ag}^{0}$ and, consequently, we can assume that photo-induced diffusion of AgNPs on DNA double helix takes place along with activation of silver atoms desorption energy which equals to $80 \mathrm{~kJ} / \mathrm{M} \mathrm{Ag}^{0}$ 
and thus we can state that the energy of $\mathrm{Ag}^{0}$ interaction with DNA double helix is not less than $80 \mathrm{~kJ} / \mathrm{M} \mathrm{Ag}^{0}$. In accordance with the Gibbs Equation

$$
\Delta G=-R T \ln K
$$

and taking into account the evaluated energy $80 \mathrm{~kJ} / \mathrm{M}$ $\mathrm{Ag}^{0}$, we assume that the stability constant of the complex is not less than $10^{14}$ and, consequently, life time of the complexes is equal to $10^{4} \mathrm{~s}$. Life-times of $1 \mathrm{~s}$ order and more are characteristic for inter-strand interactions with the participation of transition metal ions, so called crosslinks [22]. As far as in 1969 Wilhelm and Daune [23] showed that $\mathrm{Ag}^{+}$ions form cross-links between DNA chains thus releasing protons bound with $\mathrm{N}_{1}$ guanine and $\mathrm{N}_{3}$ thymine into the solution. We have estimated stability constants of $\mathrm{Cu}^{+}$and $\mathrm{Ag}^{+}$ions with DNA which are equal to $\mathrm{pK}=10.8$ for $\mathrm{Ag}^{+}$and $\mathrm{pK}=14.9$ for $\mathrm{Cu}^{+}$. Thereafter the change of free energy for $\mathrm{Ag}^{+}$is $63 \mathrm{~kJ} / \mathrm{mol}$ and 86 $\mathrm{kJ} / \mathrm{mol}$ for $\mathrm{Cu}^{+}$and lifetimes are $0.63 \mathrm{~s}$ for $\mathrm{Ag}^{+}$and $8.6 \times$ $10^{3} \mathrm{~s}$ for $\mathrm{Cu}^{+}[4]$.

\section{Conclusion}

Using spectrophotometry and thermodynamic approaches we have shown that 1) at interaction with DNA, AgNPs are adsorbed on it and only partial corrosion of nanoparticles at the level of $\mathrm{Ag}^{+}$ions is observed; 2) at photoirradiation ( $\lambda=436 \mathrm{~nm}$ or full spectrum of visible band) desorption of silver atoms from the surface of AgNPs takes place. AgNPs undergo photo-diffusion on DNA surface making prolate stretched structure (AgNPs absorption spectrum width is changed from $140 \mathrm{~nm}$ to 360 $\mathrm{nm}$ at half-height); 3) Kinetic study of photo-desorption has made it possible to determine desorption rate constant $k_{d}$ and adsorption heat $Q_{a}$ that are equal to $k_{d} \cong 9 \times$ $10^{-5} \mathrm{~s}^{-1} ; Q_{a} \geq 80 \mathrm{~kJ} / \mathrm{M} \mathrm{Ag}^{0}$ for AgNPs bound with DNA; It is shown that AgNPs represent liquid drops which moisture the DNA surface at interaction. At photo-irradiation of AgNPs-DNA complex DNA dependant conformational transition takes place due to fast and intensive heating.

\section{Acknowledgements}

The authors express their gratitude to Prof. J. Monaselidze for useful discussions and to Mrs. G. Nizharadze for her help in preparing the manuscript.

The work was partly supported by Shota Rustaveli National Science Foundation grant number GNSF/ST09 508 2-230.

\section{REFERENCES}

[1] V. G. Bregadze, Z. G. Melikishvili, T. G. Giorgadze, J. R. Monaselidze, Z. V. Jaliashvili and T. B. Khuskivadze, "Point Defects in Double Helix Induced by Interaction of
Silver Nanoparticles with DNA," 2012.

http://arxiv.org/ftp/arxiv/papers/1206/1206.4816.pdf

[2] G. Natile and F. Cannito, "Platinum Drugs, Nucleotides and DNA: The Role of Interligand Interactions," In: N. Hadjiliadis and E. Sletten, Eds., Metale Complex-DNA Interactious, Blackwell Publishing Ltd., Chichester, 2009, pp. 135-173. doi:10.1002/9781444312089.ch5

[3] V. Morchan and A. Grandas, "Platinated Oligonucleotides: Synthesis and Applications for the Control of Gene Expression," In: N. Hadjiliadis and E. Sletten, Eds., Metale Complex-DNA Interactious, Blackwell Publishing Ltd., Chichester, 2009, pp. 273-300. doi:10.1002/9781444312089.ch9

[4] V. G. Bregadze, I. G. Khutsishvili, J. G. Chkhaberidze and K. Sologashvili, "DNA as a Mediator for Proton, Electron and Energy Transfer Induced by Metal Ions," Inorganica Chimica Acta, Vol. 339, 2002, pp. 145-159. doi:10.1016/S0020-1693(02)01037-X

[5] T. Niidome, A. Shiotani, Y. Akiyame, A. Ohga, K. Nose, D. Pissuwan and Y. Niidome, "Theragnostic Approaches Using Gold Nanorods and near Infrared Ligh," Yakugaku Zasshi, Vol. 130, No. 12, 2010, pp. 1671-1667. doi:10.1248/yakushi.130.1671

[6] N. Khlebtsov and L. Dykman, "Biodistribution and Toxicity of Engineered Gold Nanoparticles: A Review of in Vitro and in Vivo Studies," Chemical Society Reviews, Vol. 40, No. 3, 2011, pp. 1647-1671. doi: $10.1039 / \mathrm{c} 0 \mathrm{cs} 00018 \mathrm{c}$

[7] B. S. Sekhon and S. R. Kamboj, "Inorganic Nanomedicine-Part 2," Nanomedicine, Vol. 6, No. 5, 2010, pp. 612618. doi:10.1016/j.nano.2010.04.003

[8] F. Ratto, P. Matteini, S. Centi, F. Rossi and R. Pini, "Gold Nanorods as New Nanochromophores for Photothermal Therapies," Journal of Biophotonics, Vol. 4, No. 1-2, 2011, pp. 64-73. doi:10.1002/jbio.201000002

[9] D. Pissuwan, S. Valenzuela and M. B. Cortie, "Prospects for gold nanorod particles in diagnostic and therapeutic applications," Biotechnol. Genet. Eng. Rev., Vol. 25, No. 1, 2008, pp. 93-112. doi:10.5661/bger-25-113

[10] J. R. Whitney, S. Sarkar, J. Zhang, T. Do, T. Young, M. K. Manson, T. A. Campbell, A. A. Puretzky, C. M. Rouleau, K. L. More, D. B. Geohegan, C. G. Rylander, H. C. Dorm and M. N. Rylander, "Single Walled Carbon Nanohorns as Photothermal Cancer Agents," Lasers in Surgery and Medicine, Vol. 43, No. 1, 2011, pp. 43-51. doi: $10.1002 / 1 \mathrm{sm} .21025$

[11] J. W. Fisher, S. Sarkar, C. F. Buchanan, C. S. Szot, J. Whitney, H. C. Hatcher, S. V. Torti, C. G. Rylander and M. N. Rylander, "Photothermal Response of Human and Murine Cancer Cells to Multiwalled Carbon Nanotubes after Laser Irradiation," Cancer Research, Vol. 70, No. 23, 2010, pp. 9855-9864.

[12] S. Yanari and F. A. Bovey, "Interpretation of Ultraviolet Spectral Changes of Proteins," Journal of Biological Chemistry, Vol. 235, No. 10, 1960, pp. 2818-2826.

[13] S. Nir, S. Abams, and R. Rein, "Polarizability Calculations on Water, Hydrogen, Oxygen, and Carbon Dioxide," Journal of Chemical Physics, Vol. 59, No. 6, 1973, pp. 3341-3355. doi:10.1063/1.1680478 
[14] The Effect of Size on Optical Properties: Data of Firm NanoComposix, Silver Nanoparticles: Optical Properties. http://nanocomposix.com/kb/silver/optical-properties

[15] The Effect of Aggregation on Optical Properties: Data of Firm NanoComposix, Silver Nanoparticles: Optical Properties. http://nanocomposix.com/kb/silver/optical-properties

[16] M. V. Volkenshtein, "Molecular Biophysics," Nauka, Moscow, 1975.

[17] A. S. Davidov, "Theory of Molecular Excitons," McGrow -Hill Book Company, New York, 1962.

[18] I. Tinoco, Jr., A. Halpern and W. T. Simpson, "The Relation between Conformation and Light Absorbtion in Polypeptides and Proteins," In: M. A. Stahmann, Ed., Polyaminoacids, Polypeptides and Proteins, University of Wisconsin Press, Madison, 1962, pp. 147-160.

[19] K. Higasi, H. Baba and A. Rembaum, "Quantum Organic
Chemistry," Nterscience Publishers, New York, 1965.

[20] V. G. Bregadze, Z. G. Melikishvili and T. G. Giorgadze, "Conformational Transitions in Silver Nanoparticles: DNA and Photoirradiation," 2012.

http://arxiv.org/ftp/arxiv/papers/1206/1206.4815.pdf

[21] Chemical Encyclopaedia (in Russian), "Clusters," Vol. 2, Sovetskaia Entsiklopedia, Moscow, 1990.

[22] V. G. Bregadze, "Metal Ion Interactions with DNA: Considerations on Structure, Stability, and Effects from Metal Ion Binding" In: A. Sigel and H. Sigel, Eds., Metal Ions in Biological Systems, Vol. 32, Marcel Dekker, New York, 1996, pp. 419-451.

[23] F. X. Wilhelm and M. Daune, "Interactions des Ions Métalliques Avec le DNA. III. Stabilité et Configuration des complexes Ag-DNA," Biopolymers, Vol. 8, No. 1, 1969, pp. 121-137. doi:10.1002/bip.1969.360080110 